\title{
Chronisch entzündliche Darmerkrankungen
}

\section{5_ Vom Symptom zur Diagnose}

\section{9_CME-Fragen}

Prof. Dr. med. Jörg C. Hoffmann

40_Langzeitbetreuung

Chefarzt der Medizinischen Klinik I

St. Marien- und St. Annastiftskrankenhaus

Ludwigshafen

In Zusammenarbeit mit der

Bayerischen Landesärztekammer

Direkt online teilnehmen unter www. cme-punkt. de

\section{Morbus Crohn und Colitis ulcerosa}

\section{Bei jungen Frauen leicht als Magersucht verkannt}

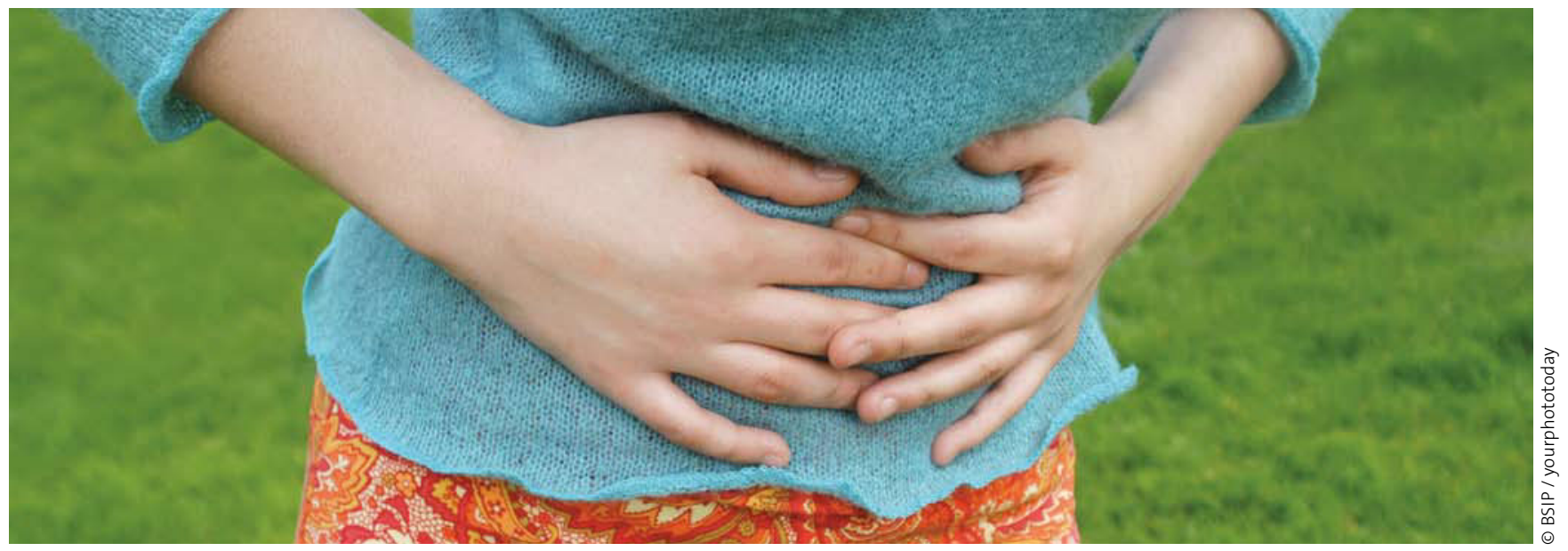

- Stellen Sie sich vor, Sie müssten zwanzigmal am Tag mit Durchfall zur Toilette und hätten dazu Bauchschmerzen und Fieber - nicht nur kurz, sondern immer wieder. So ähnlich geht es Betroffenen von chronisch entzündlichen Darmerkrankungen. Nicht selten wird das Thema „Durchfall“ in der Bevölkerung tabuisiert oder nicht ernst genommen. Wenn Bauchschmerzen und Gewichtsabnahme im Vordergrund stehen, werden gerade junge Frauen leicht mit der Diagnose „Magersucht" versehen.
Menschen mit chronisch entzündlichen Darmerkrankungen (CED) kommen mit ihren Beschwerden als Erstes zum Hausarzt oder Internisten, nicht zum Gastroenterologen. Damit die Diagnose so schnell wie möglich gestellt werden kann, ist es wichtig, dass diese Krankheitsbilder in ihren Grundzügen vielen Kollegen bekannt sind. Erschwert wird die Diagnose „Morbus Crohn“ oder „Colitis ulcerosa“ durch die Differenzialdiagnosen insbesondere des Durchfalls oder auch des Bauchschmerzes sowie die Häufigkeit oder besser die Seltenheit der CED. Obwohl knapp 400000 Betroffene in Deutschland leben, betreut der durchschnittliche Hausarzt nur vier Patienten. Gleichzeitig hat aber kaum jemand so viel Erfahrung in der Behandlung chronisch Kranker und deren sozialem Umfeld wie er. Dieser Fortbildungsschwerpunkt soll deshalb helfen, einerseits früh eine CED zu diagnostizieren und akut zu behandeln, aber vor allem auch einen Einblick in die Langzeittherapie und deren Probleme zu geben. Vielleicht können die nachfolgenden Artikel einen Beitrag dazu leisten, dass junge Menschen früher diagnostiziert werden und in der Langzeittherapie seltener Kortisondauertherapien mit all ihren $\mathrm{Ne}$ benwirkungen erhalten. 